\title{
Active transcriptomic and proteomic reprogramming in the $C$. elegans nucleotide excision repair mutant xpa-1
}

\author{
Henok Kassahun ${ }^{1}$ and Hilde Nilsen ${ }^{1, \hbar * *}$ \\ 'The Biotechnology Centre; University of Oslo; Oslo, Norway \\ ${ }^{\dagger}$ Current affiliation: Institute of Clinical Medicine; University of Oslo; Oslo, Norway; and Akershus University Hospital; Lørenskog, Norway
}

Keywords: base excision repair, nucleotide excision repair, DNA damage, transcriptome, proteome, lifespan

*Correspondence to: Hilde Nilsen; Email: hilde.nilsen@medisin.uio.no
$\mathrm{O}$ xidative stress promotes human aging and contributes to common neurodegenerative diseases. Endogenous DNA damage induced by oxidative stress is believed to be an important promoter of neurodegenerative diseases. Although a large amount of evidence correlates a reduced DNA repair capacity with aging and neurodegenerative disease, there is little direct evidence of causality. Moreover, the contribution of oxidative DNA damage to the aging process is poorly understood. We have used the nematode Caenorhabditis elegans to study the contribution of oxidative DNA damage and repair to aging. C. elegans is particularly well suited to tackle this problem because it has a minimum complexity DNA repair system, which enables us to circumvent the important limitation presented by the extensive redundancy of DNA repair enzymes in mammals.

\section{Oxidative DNA Damage and Aging in C. elegans}

The free radical theory of aging is an example of a hypothesis that, because it intuitively makes sense, is attractive both to scientists and to the general public. The theory has been enormously influential and has inspired scientists to test its implications ever since its first formulation by Denham Harman. ${ }^{1}$ As such it is a good theory because it suggests many testable hypotheses. However, few experiments have provided direct support of the original theory. This has led to the formulation of many offshoots like the mitochondrial theory of aging and the stochastic damage accumulation theory of aging.

One prediction that can be made from all of these theories is that oxidative damage to cellular macromolecules contributes to the progressive loss of function associated with aging. As DNA, unlike other cellular macromolecules, cannot be replaced in its entirety, it seems logical that maintenance of genomic stability would promote longevity and limit functional loss during aging.

A role for passive and stochastic accumulation of oxidative DNA damage in aging is often dismissed by scientists outside the DNA repair field for three principal reasons; first, even though levels of reactive oxygen species (ROS) increase with age $e^{2,3}$ and DNA repair capacity diminishes with age, ${ }^{4}$ it has been difficult to unequivocally show that oxidative DNA damage accumulates with age. Also, since a plethora of different types of DNA lesions are induced by ROS, it is not entirely clear which types of lesions are more relevant to the aging phenotype. Second, there is no good correlation between mutation accumulation and aging. ${ }^{5-7}$ Third, mutants that fail to repair oxidative DNA damage show normal lifespan. However, there are technical and biological factors that would explain these observations and further research is needed to determine whether and how oxidative DNA damage contributes to aging.

\section{Segmental Progeroid NER Syndromes}

It is often overlooked that DNA damage may not only be mutagenic, but also 


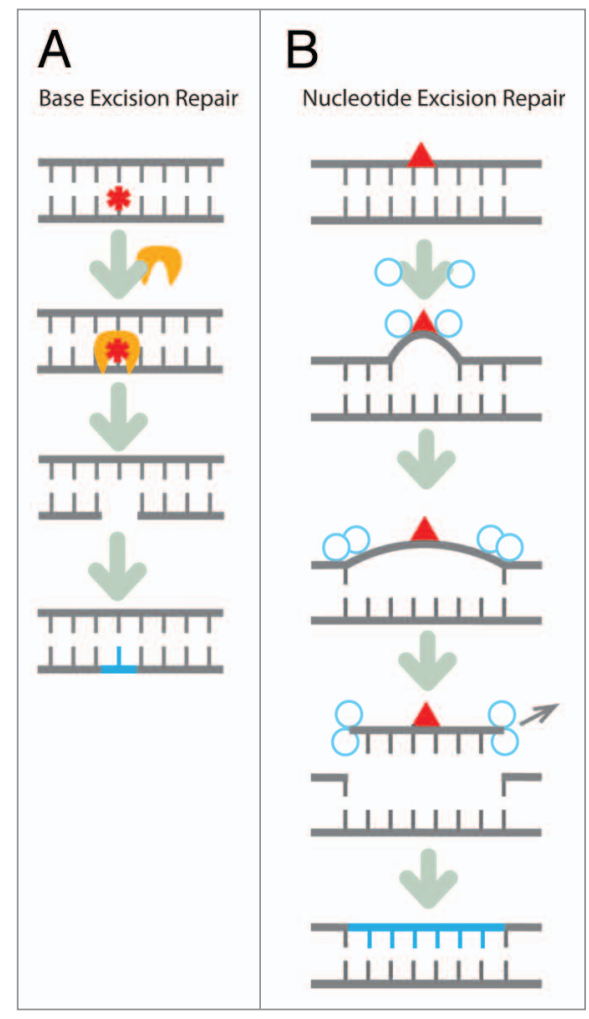

Figure 1. BER and NER pathways. Base excision repair (BER) and nucleotide excision repair (NER) are two DNA repair pathways with different, but overlapping substrates. In BER, a damaged DNA base is specifically identified by a DNA glycosylase. The damaged nucleotide is flipped out of the DNA helix into the active site pocket where the base is released as a free base. The damaged nucleotide is replaced by specialized DNA polymerases in a very short repair patch, usually one nucleotide. DNA glycosylases have relatively narrow substrate specificities. In contrast, NER recognizes DNA damage, not based on the specific modification, but as a covalent modification of DNA that also induces a structural distortion of the DNA helix. The lesion is recognized through several steps and removed as part of an oligonucleotide fragment that is sealed by replicative DNA polymerases.

cytotoxic. The mutagenic properties of DNA damage are important in mitotic cells where they give rise to mutations. ${ }^{8}$ The cytotoxic lesions are more relevant to aging and functional decline in postmitotic tissues where DNA damage does not give rise to mutations through cell division. Instead the damage may persist and cause constitutive problems e.g., with transcription. ${ }^{9}$ The existence of accelerated aging syndromes caused by DNA repair defects supports the general idea that persistent DNA damage promotes aging and age-related pathology. Studies of syndromes caused by defects in Nucleotide Excision Repair (NER), a pathway that deals with DNA damage induced by UV-light and other lesions that induce structural distortions in the DNA helix, have been highly influential (Fig. 1). A subset of patients lack the ability to preferentially perform NER in transcribed genes, so-called transcription-coupled NER (TC-NER), and mimic many, but not all, characteristics of normal aging. ${ }^{10,11}$ Studies of cell lines isolated from these segmental progeroid NER-defective patients and mouse models that mimic their phenotypes have been particularly influential. As oxidative stress is associated with aging and age-related pathology, it is believed that oxidative DNA damage that interferes with transcription is more likely to cause the segmental progeroid phenotype.

\section{Oxidative DNA Damage as a Basis for Age-Related Pathology}

Another DNA repair pathway is, however, far more important than NER for repair of oxidative DNA damage; the base excision repair (BER) pathway (Fig. 1). Still, accelerated aging syndromes are not seen in BER-deficient mouse models. This apparent paradox led to the idea that the segmental progeroid NER-defective syndromes result from accumulation of specific types of oxidative DNA damage that are repaired by NER but not BER. A class of oxidative base lesions known to be repaired by NER but not BER are the cyclopurines $\left(5^{\prime} R\right)-8,5^{\prime}$-cyclo-2'-deoxyguanosine (cdG) and $\left(5^{\prime} S\right)-8,5^{\prime}$-cyclo-2'-deoxyadenosine (cdA) 8,5'-cyclopurines. ${ }^{12,13}$ These lesions have received much attention, but whereas some studies report a correlation between the level of these cyclopurines in NER mutants, ${ }^{14}$ many studies have also reported lower levels of cyclopurines. ${ }^{15,16}$ Moreover, although segmental progeroid NER models show extreme progeroid phenotypes, many other human diseases and mouse models defective in DNA repair and DNA damage response pathways other than NER show accelerated aging phenotypes. ${ }^{17-20}$ Thus, many independent lines of evidence suggest that DNA damage contributes to aging and age-related pathology, but that cyclopurines, or possibly other NERspecific lesions, are not the only relevant lesions to consider.

\section{Base Excision Repair in C. elegans}

We were particularly interested to study the role of BER in aging as this pathway removes the vast majority of the more than 100 different types of oxidative DNA damage described. ${ }^{21}$ In BER, DNA damage is detected and excised by DNA glycosylases (Fig. 1). In mammalian cells, there are at least 11 different DNA glycosylases with partly overlapping substrate specificities. The lack of adverse phenotypes and reduced lifespan in mutants of these DNA glycosylases is generally ascribed to redundancy. In contrast, only two DNA glycosylases have been described in $C$. elegans; The UNG-1 uracil-DNA glycosylase, ${ }^{22-24}$ and the endonuclease III homolog NTH1.25 Like its mammalian counterpart, the NTH-1 DNA glycosylase has activity on oxidized pyrimidines. Following DNA damage excision by the DNA glycosylase, BER proceeds by a series of damageindependent steps. First, the abasic site left by the DNA glycosylase is incised by an AP endonuclease. C. elegans has two AP endonucleases, EXO-3 and APN-1, ${ }^{26}$ with non-redundant functions. ${ }^{27,28}$ This creates a substrate for a DNA polymerase, which fills in the gap. The nicked DNA is sealed by a DNA ligase. ${ }^{29}$ Hence, C. elegans has a minimal-complexity BER system. As C. elegans is also widely used to study genetic factors influencing longevity, ${ }^{30}$ it is well suited to reveal aging-related phenotypes that may be masked in mammals due to extensive redundancy.

\section{Lifespan of C. elegans DNA Repair Mutants}

If passive accumulation of oxidative DNA damage causes accelerated aging, we would expect $C$. elegans nth- 1 mutants to have reduced lifespan. However, nth-1null mutants showed normal mean and maximum lifespan. ${ }^{31}$ This suggests that extensive redundancy was not a reason for the lack of accelerated aging in DNA glycosylase-deficient mice. In fact, this would support the prevailing idea that BER substrates do not contribute to aging. 
So what about NER substrates-do they contribute to aging in $C$. elegans? In $C$. elegans, global genome repair (GG-NER) primarily protects germ cells and early embryos whereas transcription-coupled repair (TC-NER) becomes more important in later developmental stages. ${ }^{32}$ TC-NER is initiated by stalling of RNA polymerase II on a lesion, whereas GG-NER depends on UV-DDB and XPC-1/hHR23 for DNA-damage detection. ${ }^{33}$ Both branches depend on XPA-1 for damage verification and formation of the preincision complex. ${ }^{34}$ As expected, $x p a-1$ mutants are UV-sensitive and have reduced capacity to repair UV-induced DNA damage (see ref. 35 for a recent review). Importantly, xpa-1 mutants are not expected to accumulate DNA repair intermediates like single-stranded breaks or gaps, which would have more severe consequences than accumulation of the oxidized base itself. Using this strain we could show that NER indeed contributes to repair of oxidative DNA damage in C. elegans as the steady-state levels of the oxidized DNA bases formamidopyrimidines (FapyGua and FapyAde) and 8-hydroxyadenine (8-OH Ade), which are classical BER substrates, are significantly increased in xpa-1 (ok698) mutants. ${ }^{36}$

Contradictory reports exist as to whether NER-deficient $x p a-1$ mutants have shortened lifespan (discussed in ref. 35). In the original screen to identify UV-sensitive mutants, xpa-1(ok698) was referred to as having a near normal lifespan. ${ }^{37}$ Hyun et al. reported a 5-6 d reduction in mean lifespan, whereas no reduced lifespan was found in other studies. ${ }^{38}$ Lans et al. found some reduction in mean lifespan when measuring an unbiased population but no reduction when assessing the lifespan only of apparently healthy looking animals. ${ }^{32,39}$ In our laboratory we have measured the mean lifespan of an unbiased population and found a 3-4 d reduced mean lifespan, but no reduction in maximum lifespan when the animals fed on OP50. ${ }^{31}$ This result was independently confirmed in a collaborating laboratory which also showed that normal median lifespan was regained if we grow the same strain on $E$. coli HT115(DE3). ${ }^{36}$ Hence, the lifespan of $x p a-1$ mutants is somewhat shorter than the isogenic wild-types, but it is influenced by external factors such as nutrition. Phenotypic variation induced by diet is well known in C. elegans and impinges on many of the same processes that are regulated in DNA repair mutants. ${ }^{40-42}$ How to adjust for these effects in e.g., RNAi feeding experiments will be a future challenge.

\section{Hormesis Maintains Wild- Type Phenotypes in DNA Repair Mutants}

Systematic gene expression profiling has given valuable insight into the phenotypes of segmental progeroid NERdefective mice. They show a characteristic gene expression pattern with suppression of the insulin-like signaling (ILS) and activation of oxidative stress response pathways. ${ }^{43-46}$ The transcriptomic modulation in segmental progeroid NER mutants is believed to reflect a "survival response" 47,48 since suppression of ILS through caloric restriction is associated with lifespan extension. ${ }^{49,50}$ Similarly, characterizing the transcriptomic signatures of $C$. elegans xpa-1 mutants has proved to be highly informative toward understanding how normal-or near-normal-phenotypes are maintained in the absence of effective DNA repair. As expected from the near normal phenotype, $x p a-1$ mutants do not show the extensive transcriptomic modulation seen in segmental progeroid NER-defective mice. However, we, ${ }^{31,36}$ and others, ${ }^{51}$ identified a small yet informative set of genes differentially expressed in $x p a-1$ mutants. Gene set enrichment analyses (GSEA) revealed that the biological process (BP) "determination of adult lifespan" was the only overrepresented BP among the regulated genes. This is likely not due to a suppression of ILS, but rather reflects the interrelation of oxidative stress responses and ILS signaling in C. elegans. Overexpression and nuclear translocation of the SKN-1 target gene GST-4 confirmed that $x p a-1$ mutants experience oxidative stress. ${ }^{31,36}$ We also used quantitative proteomics to assess whether the transcriptomic signatures were reflected at the level of the proteome. We used a newly developed technique called isobaric peptide terminal labeling (IPTL) technology, ${ }^{52}$ which can be used to label proteins in freshly prepared extracts from whole worms ${ }^{36}$ or from isolated tissues like the germline. ${ }^{53}$ It is a very good alternative for $C$. elegans proteomic studies where metabolic labeling has some limitations. Whereas stable isotope labeling by amino acids in cell culture (SILAC) has been used to analyze several multicellular organisms, problems associated with the conversion of isotope-labeled arginine to proline and other amino acids have complicated such studies in C. elegans. ${ }^{54}$ The proteomic data set of $x p a-1$ mutants was characterized by upregulation of proteins annotated as positive regulators of growth and development. ${ }^{36}$ Although many of the differentially expressed proteins are annotated as oxidative-stress responsive, we did not see a direct correlation between the transcriptomic and proteomic signatures. In our opinion, this is also not to be expected. But we would expect that the regulated proteins were somehow linked to the regulated transcripts, for example, as targets of stress-responsive transcription factors. The FunCoup browser is a web-based tool developed to extract functional links (or interactions) between genes, RNA, and proteins. ${ }^{55}$ When we performed GSEA after including direct interactors of the primary transcriptomic and proteomic data sets, the two signatures showed remarkable similarities. ${ }^{36}$ We could also demonstrate that the phenotypic consequences of depleting these genes were more severe in the mutant than in the wild-type, which is expected if these changes are indeed part of a survival response.

\section{Does Accumulation of Cyclopurines Cause the Reduced Lifespan of xpa-1?}

To address the important question of whether transcriptional and proteomic modulation in $x p a-1$ mutants result from accumulation of cyclopurines, we measured these lesions in DNA isolated from whole worm extracts. We found that the steady-state levels of cdA and cdG were reduced in $x p a-1$ mutants, which argues against the notion that stochastic accumulation of these lesions is the cause of lifespan reduction. Although it is possible that accumulation of lesions in a 
few subsets of cells could be important, our observation that deletion of the BER enzyme NTH-1 restored normal lifespan in the $x p a-1$ mutants and suppressed the characteristic upregulation of oxidative stress response genes in xpa-1 mutants, ${ }^{31}$ are difficult to reconcile with passive accumulation of DNA damage being the instigator of these complex phenotypes. Instead, this suggests that reprogramming of $x p a-1$ mutants is an active response. We substantiated this idea by showing that also transient depletion of NTH-1 by RNAi reversed the upregulation of transcript levels in $x p a-1$ mutants. We proposed therefore that in the $x p a-1$ mutants, DNA damage is bound, but inefficiently or aberrantly processed by NTH-1 to generate a genomic stress signal more potent than the original lesion itself. The important future direction of this research would be to decipher how this is translated into reprogramming of the cell and the entire animal. There are indications that this involves ROS and activation of stress-responsive kinases. NTH-1 is an Fe-S cluster-containing protein that can utilize DNA charge transport mechanisms to identify DNA damage. DNA charge transport has been suggested to activate MAPK signaling. ${ }^{56,57}$ MAPK activation was also suggested from transcriptome analysis of another NER mutant, $\operatorname{ercc-1} 1^{39}$, where we found a strong correlation between genes regulated by the PMK-1 p38 MAPK and the ercc-1 data set. Together, these results suggest that NER function is not lifespan-limiting in C. elegans partially due to an adaptive transcriptome reprogramming involving activation of p38 MAPK stress-response signaling. As such, the DNA repair deficiency can be seen as a mild stressor that induces a favorable biological response. Our recent data demonstrate that these hormetic responses mould phenotypes induced by various stressors in C. elegans BER and NER mutants. In some cases, the hormetic response to DNA repair deficiency seems to be the most important determinant of phenotypes; apoptosis induced by the oxidizing agent paraquat is, for example, impaired in BER mutants ${ }^{23}$ as a result of increased p38 MAPK activation in these mutants (Kassahun and Nilsen, manuscript in preparation). Furthermore, NER mutants was recently shown to be more resistant to heat stress after being treated with low doses of UV light and a role for the ERK MAP kinase MPK-1 in mediating a signal between cell death and organismal stress resistance was demonstrated..$^{58}$ However, one should remember that no agent used to induce DNA damage can do so without also inducing ROS. Hence, there will always be a complex cellular reaction to DNA damaging agents-and not all effects observed after exposure to e.g., UV-light will originate directly from DNA damage. The possibility that ROS formation may modulate phenotypic outcomes may be an important factor to consider, particularly in the $C$. elegans system, which seems to employ highly sophisticated systemic stress responses.

\section{Concluding Remarks}

The contribution of oxidative DNA damage to aging and the functional deterioration associated with aging is still debated. Our recent data suggest that DNA damage does contribute to aging, but that accumulation of specific types of lesions is not in itself sufficient to cause a shorter lifespan. Instead, unproductive processing of DNA damage may generate a genomic stress signal that leads to lifespan reduction. To further understand the causal relationship between oxidative DNA damage and aging or age-related diseases, it is important understand how DNA damage is bound, sensed, and processed by different DNA repair pathways and to understand the crosstalk between different pathways. Moreover, it is important to understand how compensatory reprogramming of DNA repair mutants affect phenotypic readouts. Whether the mechanisms that operate to determine lifespan in DNA repair mutants are also relevant to normal aging remains an open question but $C$. elegans is among the best model systems to tackle these issues by combining genetics, molecular, and computational strategies.

\section{Disclosure of Potential Conflicts of Interest}

No potential conflicts of interest were disclosed.

\section{Acknowledgments}

We thank Hanne Baadsgaard Utigard (Communications Department; University of Oslo) for designing the figures.

\section{References}

1. Harman D. Aging: a theory based on free radical and radiation chemistry. J Gerontol 1956; 11:298300; PMID:13332224; http://dx.doi.org/10.1093/ geronj/11.3.298

2. Nabben M, Hoeks J, Briedé JJ, Glatz JF, MoonenKornips E, Hesselink MK, Schrauwen P. The effect of UCP3 overexpression on mitochondrial ROS production in skeletal muscle of young versus aged mice. FEBS Lett 2008; 582:4147-52; PMID:19041310; http://dx.doi.org/10.1016/j.febslet.2008.11.016

3. Sohal RS, Sohal BH. Hydrogen peroxide release by mitochondria increases during aging. Mech Ageing Dev 1991; 57:187-202; PMID:1904965; http:// dx.doi.org/10.1016/0047-6374(91)90034-W

4. Gredilla R, Garm C, Holm R, Bohr VA, Stevnsner T. Differential age-related changes in mitochondrial DNA repair activities in mouse brain regions. Neurobiol Aging 2010; 31:993-1002 PMID:18701195; $\quad$ http://dx.doi.org/10.1016/j. neurobiolaging.2008.07.004

5. Vijg J, Dollé ME. Large genome rearrangements as a primary cause of aging. Mech Ageing Dev 2002; 123:907-15; PMID:12044939; http://dx.doi. org/10.1016/S0047-6374(02)00028-3

6. Hoeijmakers JH. DNA damage, aging, and cancer. N Engl J Med 2009; 361:1475-85; PMID: 19812404 ; http://dx.doi.org/10.1056/NEJMra0804615

7. Freitas AA, de Magalhães JP. A review and appraisal of the DNA damage theory of ageing. Mutat Res 2011; 728:12-22; PMID:21600302; http://dx.doi. org/10.1016/j.mrrev.2011.05.001

8. Barnes DE, Lindahl T. Repair and genetic consequences of endogenous DNA base damage in mammalian cells. Annu Rev Genet 2004; 38:44576; PMID:15568983; http://dx.doi.org/10.1146/ annurev.genet.38.072902.092448

9. Garinis GA, Uittenboogaard LM, Stachelscheid H, Fousteri M, van Ijcken W, Breit TM, van Steeg $\mathrm{H}$, Mullenders LH, van der Horst GT, Brüning JC, et al. Persistent transcription-blocking DNA lesions trigger somatic growth attenuation associated with longevity. Nat Cell Biol 2009; 11:60415; PMID:19363488; http://dx.doi.org/10.1038/ ncb1866

10. Niedernhofer LJ, Garinis GA, Raams A, Lalai AS, Robinson AR, Appeldoorn E, Odijk H, Oostendorp R, Ahmad A, van Leeuwen W, et al. A new progeroid syndrome reveals that genotoxic stress suppresses the somatotroph axis. Nature 2006; 444:103843; PMID:17183314; http://dx.doi.org/10.1038/ nature 05456

11. Tian M, Shinkura R, Shinkura N, Alt FW. Growth retardation, early death, and DNA repair defects in mice deficient for the nucleotide excision repair enzyme XPF. Mol Cell Biol 2004; 24:1200-5; PMID:14729965; http://dx.doi.org/10.1128/ MCB.24.3.1200-1205.2004

12. Kuraoka I, Bender C, Romieu A, Cadet J, Wood RD, Lindahl T. Removal of oxygen free-radical-induced 5',8-purine cyclodeoxynucleosides from DNA by the nucleotide excision-repair pathway in human cells. Proc Natl Acad Sci U S A 2000; 97:38327; PMID:10759556; http://dx.doi.org/10.1073/ pnas. 070471597 
13. Brooks PJ, Wise DS, Berry DA, Kosmoski JV, Smerdon MJ, Somers RL, Mackie H, Spoonde AY, Ackerman EJ, Coleman K, et al. The oxidative DNA lesion $8,5^{\prime}-(S)$-cyclo-2'-deoxyadenosine is repaired by the nucleotide excision repair pathway and blocks gene expression in mammalian cells. J Biol Chem 2000; 275:22355-62; PMID:10801836; http:// dx.doi.org/10.1074/jbc.M002259200

14. Kirkali G, de Souza-Pinto NC, Jaruga P, Bohr VA, Dizdaroglu M. Accumulation of (5'S)-8,5'-cyclo2 -deoxyadenosine in organs of Cockayne syndrome complementation group B gene knockout mice. DNA Repair (Amst) 2009; 8:274-8; PMID:18992371; http://dx.doi.org/10.1016/j.dnarep.2008.09.009

15. D'Errico M, Parlanti E, Teson M, de Jesus BMB, Degan P, Calcagnile A, Jaruga P, Bjørås M, Crescenzi M, Pedrini AM, et al. New functions of XPC in the protection of human skin cells from oxidative damage. EMBO J 2006; 25:4305-15; PMID:16957781; http://dx.doi.org/10.1038/sj.emboj.7601277

16. D'Errico M, Parlanti E, Teson M, Degan P, Lemma T, Calcagnile A, Iavarone I, Jaruga P, Ropolo M, Pedrini AM, et al. The role of CSA in the response to oxidative DNA damage in human cells. Oncogene 2007; 26:4336-43; PMID:17297471; http://dx.doi. org/10.1038/sj.onc. 1210232

17. Martin GM, Oshima J. Lessons from human progeroid syndromes. Nature 2000; 408:263-6; PMID:11089984; http://dx.doi. org/10.1038/35041705

18. Wong K-K, Maser RS, Bachoo RM, Menon J, Carrasco DR, Gu Y, Alt FW, DePinho RA. Telomere dysfunction and Atm deficiency compromises organ homeostasis and accelerates ageing. Nature 2003; 421:643-8; PMID:12540856; http://dx.doi. org/10.1038/nature01385

19. Tyner SD, Venkatachalam S, Choi J, Jones S, Ghebranious N, Igelmann $\mathrm{H}, \mathrm{Lu} \mathrm{X}$, Soron G, Cooper B, Brayton C, et al. p53 mutant mice that display early ageing-associated phenotypes. Nature 2002; 415:45-53; PMID:11780111; http://dx.doi. org/10.1038/415045a

20. Nisitani S, Hosokawa M, Sasaki MS, Yasuoka K, Naiki $\mathrm{H}$, Matsushita T, Takeda T. Acceleration of chromosome aberrations in senescence-accelerated strains of mice. Mutat Res 1990; 237:221-8; PMID:2079961; http://dx.doi.org/10.1016/0921-8734(90)90003-A

21. Dizdaroglu M. Oxidatively induced DNA damage: mechanisms, repair and disease. Cancer Lett 2012; 327:26-47; PMID:22293091; http://dx.doi. org/10.1016/j.canlet.2012.01.016

22. Nakamura N, Morinaga H, Kikuchi M, Yonekura S, Ishii N, Yamamoto K, Yonei S, Zhang Q-M. Cloning and characterization of uracil-DNA glycosylase and the biological consequences of the loss of its function in the nematode Caenorhabditis elegans. Mutagenesis 2008; 23:407-13; PMID:18524757; http://dx.doi. org/10.1093/mutage/gen030

23. Skjeldam HK, Kassahun H, Fensgård O, SenGupta T, Babaie E, Lindvall JM, Arczewska K, Nilsen H. Loss of Caenorhabditis elegans UNG-1 uracil-DNA glycosylase affects apoptosis in response to DNA damaging agents. DNA Repair (Amst) 2010; 9:86170; PMID:20493785; http://dx.doi.org/10.1016/j. dnarep.2010.04.009

24. Shatilla A, Ramotar D. Embryonic extracts derived from the nematode Caenorhabditis elegans remove uracil from DNA by the sequential action of uracil-DNA glycosylase and AP (apurinic/apyrimidinic) endonuclease. Biochem J 2002; 365:547-53; PMID:11966472; $\quad$ http://dx.doi.org/10.1042/ BJ20020375

25. Morinaga H, Yonekura S, Nakamura N, Sugiyama $\mathrm{H}$, Yonei S, Zhang-Akiyama Q-M. Purification and characterization of Caenorhabditis elegans NTH, a homolog of human endonuclease III: essential role of $\mathrm{N}$-terminal region. DNA Repair (Amst) 2009; 8:84451; PMID:19481506; http://dx.doi.org/10.1016/j. dnarep.2009.04.020
26. Shatilla A, Leduc A, Yang X, Ramotar D. Identification of two apurinic/apyrimidinic endonucleases from Caenorhabditis elegans by cross-species complementation. DNA Repair (Amst) 2005; 4:655 70; PMID:15907773; http://dx.doi.org/10.1016/j. dnarep.2005.02.005

27. Sengupta T, Torgersen ML, Kassahun H, Vellai T, Simonsen A, Nilsen H. Base excision repair AP endonucleases and mismatch repair act together to induce checkpoint-mediated autophagy. Nat Commun 2013; 4:2578; PMID:24154628; http://dx.doi. org/10.1038/ncomms3674

28. Zakaria C, Kassahun H, Yang X, Labbé JC, Nilsen $\mathrm{H}$, Ramotar D. Caenorhabditis elegans APN-1 plays a vital role in maintaining genome stability. DNA Repair (Amst) 2010; 9:169-76; PMID:20036200; http://dx.doi.org/10.1016/j.dnarep.2009.11.007

29. Asagoshi K, Lehmann W, Braithwaite EK, SantanaSantos L, Prasad R, Freedman JH, Van Houten B, Wilson SH. Single-nucleotide base excision repair DNA polymerase activity in C. elegans in the absence of DNA polymerase $\beta$. Nucleic Acids Res 2012; 40:670-81; PMID:21917855; http://dx.doi. org/10.1093/nar/gkr727

30. Antebi A. Genetics of aging in Caenorhabditis elegans. PLoS Genet 2007; 3:1565-71; PMID:17907808; http://dx.doi.org/10.1371/journal.pgen.0030129

31. Fensgård $\varnothing$, Kassahun $H$, Bombik I, Rognes $T$, Lindvall JM, Nilsen H. A two-tiered compensatory response to loss of DNA repair modulates aging and stress response pathways. Aging (Albany NY) 2010; 2:133-59; PMID:20382984

32. Lans H, Marteijn JA, Schumacher B, Hoeijmaker JH, Jansen G, Vermeulen W. Involvement of global genome repair, transcription coupled repair, and chromatin remodeling in UV DNA damage response changes during development. PLoS Genet 2010 6:e1000941; PMID:20463888; http://dx.doi. org/10.1371/journal.pgen.1000941

33. Naegeli H, Sugasawa K. The xeroderma pigmentosum pathway: decision tree analysis of DNA quality. DNA Repair (Amst) 2011; 10:673-83; PMID:21684221; http://dx.doi.org/10.1016/j.dnarep.2011.04.019

34. Sugasawa K, Akagi J, Nishi R, Iwai S, Hanaoka F. Two-step recognition of DNA damage for mammalian nucleotide excision repair: Directional binding of the XPC complex and DNA strand scanning. Mol Cell 2009; 36:642-53; PMID:19941824; http:// dx.doi.org/10.1016/j.molcel.2009.09.035

35. Lans H, Vermeulen W. Nucleotide Excision Repair in Caenorhabditis elegans. Mol Biol Int 2011, 2011:542795; PMID:22091407; http://dx.doi. org/10.4061/2011/542795

36. Arczewska KD, Tomazella GG, Lindvall JM, Kassahun H, Maglioni S, Torgovnick A, Henriksson J, Matilainen O, Marquis BJ, Nelson BC, et al. Active transcriptomic and proteomic reprogramming in the $\mathrm{C}$. elegans nucleotide excision repair mutant xpa-1. Nucleic Acids Res 2013; 41:5368-81; PMID:23580547; http://dx.doi.org/10.1093/nar/ gkt225

37. Hartman PS, Herman RK. Radiation-sensitive mutants of Caenorhabditis elegans. Genetics 1982; 102:159-78; PMID:7152245

38. Hyun M, Lee J, Lee K, May A, Bohr VA, Ahn B. Longevity and resistance to stress correlate with DNA repair capacity in Caenorhabditis elegans. Nucleic Acids Res 2008; 36:1380-9; PMID:18203746; http://dx.doi.org/10.1093/nar/gkm1161

39. Lans H, Lindvall JM, Thijssen K, Karambelas AE, Cupac D, Fensgård O, Jansen G, Hoeijmakers JH, Nilsen H, Vermeulen W. DNA damage leads to progressive replicative decline but extends the life span of long-lived mutant animals. Cell Death Differ 2013; 20:1709-18; PMID:24013725; http://dx.doi. org/10.1038/cdd.2013.126
40. Coolon JD, Jones KL, Todd TC, Carr BC, Herman MA. Caenorhabditis elegans genomic response to soil bacteria predicts environment-specific genetic effects on life history traits. PLoS Genet 2009; 5:e1000503; PMID:19503598; http://dx.doi.org/10.1371/journal. pgen.1000503

41. MacNeil LT, Watson E, Arda HE, Zhu LJ, Walhout AJ. Diet-induced developmental acceleration independent of TOR and insulin in C. elegans. Cell 2013; 153:240-52; PMID:23540701; http://dx.doi. org/10.1016/j.cell.2013.02.049

42. Reinke $\mathrm{SN}, \mathrm{Hu} \mathrm{X}$, Sykes $\mathrm{BD}$, Lemire $\mathrm{BD}$ Caenorhabditis elegans diet significantly affects metabolic profile, mitochondrial DNA levels, lifespan and brood size. Mol Genet Metab 2010; 100:274 82; PMID:20400348; http://dx.doi.org/10.1016/j. ymgme.2010.03.013

43. Niedernhofer LJ, Garinis GA, Raams A, Lalai AS, Robinson AR, Appeldoorn E, Odijk H, Oostendorp R, Ahmad A, van Leeuwen W, et al. A new progeroid syndrome reveals that genotoxic stress suppresses the somatotroph axis. Nature 2006; 444:103843; PMID:17183314; http://dx.doi.org/10.1038/ nature 05456

44. van der Pluijm I, Garinis GA, Brandt RM, Gorgels TG, Wijnhoven SW, Diderich KE, de Wit J, Mitchell JR, van Oostrom C, Beems R, et al. Impaired genome maintenance suppresses the growth hormone--insulin-like growth factor 1 axis in mice with Cockayne syndrome. PLoS Biol 2007; 5:e2; PMID:17326724; http://dx.doi.org/10.1371/journal.pbio.0050002

45. Garinis GA, van der Horst GT, Vijg J, Hoeijmakers JH. DNA damage and ageing: new-age ideas for an age-old problem. Nat Cell Biol 2008; 10:12417; PMID:18978832; http://dx.doi.org/10.1038/ ncb1108-1241

46. Kirkwood TB. Understanding the odd science of aging. Cell 2005; 120:437-47; PMID:15734677; http://dx.doi.org/10.1016/j.cell.2005.01.027

47. Garinis GA, Uittenboogaard LM, Stachelscheid H, Fousteri M, van Ijcken W, Breit TM, van Steeg H, Mullenders LH, van der Horst GT, Brüning JC, et al. Persistent transcription-blocking DNA lesions trigger somatic growth attenuation associated with longevity. Nat Cell Biol 2009; 11:604-15; PMID:19363488; http://dx.doi.org/10.1038/ncb1866

48. Wang J, Clauson CL, Robbins PD, Niedernhofer LJ, Wang Y. The oxidative DNA lesions 8,5'-cyclopurines accumulate with aging in a tissue-specific manner. Aging Cell 2012; 11:714-6; PMID:22530741; http://dx.doi.org/10.1111/j.1474-9726.2012.00828.x

49. Friedman DB, Johnson TE. A mutation in the age-1 gene in Caenorhabditis elegans lengthens life and reduces hermaphrodite fertility. Genetics 1988; 118:75-86; PMID:8608934

50. Kenyon C, Chang J, Gensch E, Rudner A, Tabtiang R. A C. elegans mutant that lives twice as long as wild type. Nature 1993; 366:461-4; PMID:8247153; http://dx.doi.org/10.1038/366461a0

51. Boyd WA, Crocker TL, Rodriguez AM, Leung MC, Lehmann DW, Freedman JH, Van Houten B, Meyer JN. Nucleotide excision repair genes are expressed at low levels and are not detectably inducible in Caenorhabditis elegans somatic tissues, but their function is required for normal adult life after UVC exposure. Mutat Res 2010; 683:5767; PMID:19879883; http://dx.doi.org/10.1016/j. mrfmmm.2009.10.008

52. Koehler CJ, Strozynski M, Kozielski F, Treumann A, Thiede B. Isobaric peptide termini labeling for MS/ MS-based quantitative proteomics. J Proteome Res 2009; 8:4333-41; PMID:19655813; http://dx.doi. org/10.1021/pr900425n

53. Tomazella GG, Kassahun H, Nilsen H, Thiede B. Quantitative proteome analysis reveals RNA processing factors as modulators of ionizing radiationinduced apoptosis in the C. elegans germline. J Proteome Res 2012; 11:4277-88; PMID:22757771; http://dx.doi.org/10.1021/pr300386z 
54. Larance M, Bailly AP, Pourkarimi E, Hay RT, Buchanan G, Coulthurst S, Xirodimas DP, Gartner A, Lamond AI. Stable-isotope labeling with amino acids in nematodes. Nat Methods 2011; 8:84951; PMID:21874007; http://dx.doi.org/10.1038/ nmeth.1679

55. Alexeyenko A, Sonnhammer EL. Global networks of functional coupling in eukaryotes from comprehensive data integration. Genome Res 2009; 19:110716; PMID:19246318; http://dx.doi.org/10.1101/ gr.087528.108
56. Sontz PA, Mui TP, Fuss JO, Tainer JA, Barton JK. DNA charge transport as a first step in coordinating the detection of lesions by repair proteins. Proc Nat Acad Sci U S A 2012; 109:1856-61; PMID:22308447; http://dx.doi.org/10.1073/pnas.1120063109

57. Fuss JO, Tainer JA. XPB and XPD helicases in TFIIH orchestrate DNA duplex opening and damage verification to coordinate repair with transcription and cell cycle via CAK kinase. DNA Repair (Amst) 2011; 10:697-713; PMID:21571596; http://dx.doi. org/10.1016/j.dnarep.2011.04.028
58. Ermolaeva MA, Segref A, Dakhovnik A, Ou H-L, Schneider JI, Utermöhlen O, Hoppe T, Schumache B. DNA damage in germ cells induces an innate immune response that triggers systemic stress resistance. Nature 2013; 501:416-20; PMID:23975097; http://dx.doi.org/10.1038/nature12452 